\title{
Asymptomatic Female with Multiple Tumours and Hormonal Levels 10 Times above the Normal Limits
}

\section{Mara Carsote ${ }^{1,2^{*}}$, lonela Baciu ${ }^{1,2}$ and Catalina Poiana ${ }^{1,2}$}

${ }^{1}$ Carol Davila University of Medicine and Pharmacy, Bucharest, Romania

${ }^{2}$ C.I.Parhon National Institute of Endocrinology, Bucharest, Romania

\section{Clinical Image}

32-year old female has a negative personal and family medical history but recently a cousin of hers has been identified as caring a mutation at c1900T>G, p.C634G (TGC634CGC; Cys634Gly, Exon 11) RET gene. The patient was tested and found positive, too. The elements of type II multiple endocrine neoplasia (MEN) have been identified even she was completely asymptomatic: bilateral adrenal tumors that were confirmed as benign pheocromocytomas after bilateral laparoscopic adrenalectomy (Table 1 and Figure 1), and medullar thyroid cancer suggested by extremely high calcitonin levels and confirmed after total thyroidectomy and lymph neck resection (Table 1). The two procedures were performed within one month with a good recovery. The patient started lifelong thyroid and adrenal substitution and the calcitonin as well as catecolamines became normal after surgical procedures. The silent phenotype in MEN II syndrome may underlie multiple aggressive tumors as bilateral pheocromocytoma and C-cell thyroid cancer but the diagnosis is delayed if the genetic background is unknown.

\begin{tabular}{|c|c|c|c|}
\hline Hormone & Values & Units & Normal levels \\
\hline 24-h urinary metanephrines & 3329 & Micrograms $/ 24$ hours \\
\hline 24-h urinary normetanephrines & 6956 & $\mu 50$ & $\mu 0 / 24-\mathrm{h}$ \\
\hline serum calcitonin & 264 & Picograms $/ \mathrm{milliliter}(\mathrm{pg} / \mathrm{mL})$ & 100 \\
\hline
\end{tabular}

Table 1: Hormonal panel in a 32-year completely asymptomatic female.

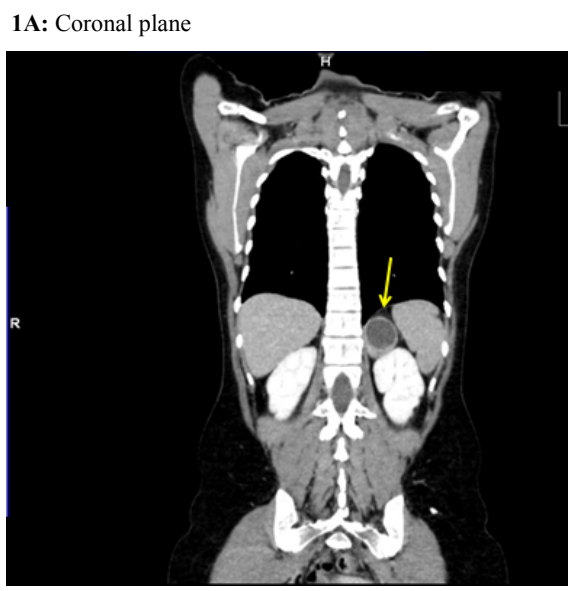

1B: Transverse plane

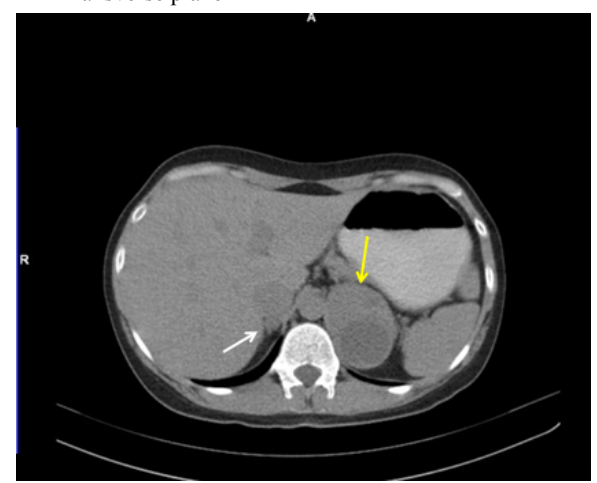

Figure 1: Abdominal (contrast) computed tomography: right tumor of $<1$ centimeter $(\mathrm{cm})$ (white arrow) and left adrenal tumor of 2.3 by $2.9 \mathrm{~cm}$ with necrosis (yellow arrow).

*Corresponding author: Mara Carsote, Aviatorilor Ave 34-36, sector 1, Bucharest, Romania, Tel: +40213172041; Fax: +40213170607; E-mail: carsote_m@hotmail.com

Received June 02, 2015; Accepted June 02, 2015; Published July 01, 2015

Citation: Carsote M, Baciu I, Poiana C (2015) Asymptomatic Female with Multiple Tumours and Hormonal Levels 10 Times above the Normal Limits. Hereditary Genet 4: i101. doi:10.4172/2161-1041.1000i101

Copyright: (c) 2015 Carsote M, et al. This is an open-access article distributed under the terms of the Creative Commons Attribution License, which permits unrestricted use, distribution, and reproduction in any medium, provided the original author and source are credited. 